University of Montana

ScholarWorks at University of Montana

$10-2010$

\title{
Explaining Long-Distance Dispersal: Effects of Dispersal Distance on Survival and Growth in a Stream Salamander
}

Winsor H. Lowe

University of Montana - Missoula, winsor.lowe@umontana.edu

Follow this and additional works at: https://scholarworks.umt.edu/biosci_pubs

Part of the Biology Commons

Let us know how access to this document benefits you.

\section{Recommended Citation}

Lowe, Winsor H., "Explaining Long-Distance Dispersal: Effects of Dispersal Distance on Survival and Growth in a Stream Salamander" (2010). Biological Sciences Faculty Publications. 277.

https://scholarworks.umt.edu/biosci_pubs/277

This Article is brought to you for free and open access by the Biological Sciences at ScholarWorks at University of Montana. It has been accepted for inclusion in Biological Sciences Faculty Publications by an authorized administrator of ScholarWorks at University of Montana. For more information, please contact scholarworks@mso.umt.edu. 


\title{
Explaining long-distance dispersal: effects of dispersal distance on survival and growth in a stream salamander
}

\author{
WinSOR H. LOWE ${ }^{1}$ \\ Division of Biological Sciences, University of Montana, Missoula, Montana 59812 USA
}

\begin{abstract}
Long-distance dispersal (LDD) may contribute disproportionately to range expansions, the creation of new evolutionary lineages, and species persistence in humandominated landscapes. However, because data on the individual consequences of dispersal distance are extremely limited, we have little insight on how LDD is maintained in natural populations. I used six years of spatially explicit capture-mark-recapture (CMR) data to test the prediction that individual performance increases with dispersal distance in the stream salamander Gyrinophilus porphyriticus. Dispersal distance was total distance moved along the $1-\mathrm{km}$ study stream, ranging from 0 to $565 \mathrm{~m}$. To quantify individual performance, I used CMR estimates of survival and individual growth rates based on change in body length. Survival and growth rates increased significantly with dispersal distance. These relationships were not confounded by pre-dispersal body condition or by ecological gradients along the stream. Individual benefits of LDD were likely caused by an increase in the upper limit of settlement site quality with dispersal distance. My results do not support the view that the fitness consequences of LDD are unpredictable and instead suggest that consistent evolutionary mechanisms may explain the prevalence of LDD in nature. They also highlight the value of direct CMR data for understanding the individual consequences of variation in dispersal distance and how that variation is maintained in natural populations.
\end{abstract}

Key words: dispersal distance; fitness; Gyrinophilus porphyriticus; habitat selection; individual consequences; leptokurtic; long-distance dispersal; movement ecology; New Hampshire, USA; population ecology; salamanders; spatial dynamics.

\section{INTRODUCTION}

Dispersal is a fundamental demographic, evolutionary, and ecological process (Wright 1951, Clobert et al. 2001, Holyoak et al. 2005). In most species, dispersal patterns are characterized by many individuals that remain close to their origin and few individuals that move far from that location (Endler 1977, Johnson and Gaines 1990). Models and theory suggest that longdistance dispersal events can contribute disproportionately to range expansions and the creation of new evolutionary lineages (Darwin 1859, Dytham 2009), species persistence in fragmented landscapes (Trakhtenbrot et al. 2005), and nonnative invasions (Caswell et al. 2003). However, empirical understanding of the causes and consequences of continuous variation in dispersal distance, including long-distance dispersal (LDD), is very limited.

At the population level, the combination of nondispersers and dispersers results in movement distributions that are leptokurtic, or "thick-tailed" (kurtosis $\left[\gamma_{2}\right]$ $>0$ ). Leptokurtic movement distributions have high concentrations of observations around a distance of 0

Manuscript received 11 August 2009; revised 5 January 2010; accepted 26 February 2010. Corresponding Editor: A. S. Flecker.

${ }^{1}$ E-mail: winsor.lowe@umontana.edu and tails encompassing variation in dispersal distance (e.g., Fig. 1). Studies have elucidated the proximal drivers of leptokurtosis, including variation among individuals in movement-related behavioral and morphological traits (e.g., Fraser et al. 2001) and variation in extrinsic habitat structure (e.g., Morales 2002). There is also evidence of fitness trade-offs associated with discrete differences in dispersal distance (e.g., Hansson et al. 2004). But because we lack information on the individual consequences of continuous variation in dispersal distance, we have little insight on how LDD is maintained in populations (Trakhtenbrot et al. 2005, Nathan 2006, Holyoak et al. 2008).

As an individual's dispersal range increases, so does the number of potential settlement sites. Assuming that most dispersers move beyond the scale at which site conditions are strongly autocorrelated, then as the number of potential settlement sites increases, so will the diversity of site conditions (Pulliam and Danielson 1991, Koenig 1999). In active dispersers that make settlement decisions based on these conditions, the upper limit of settlement site quality should, therefore, also increase with dispersal range, leading to an increase in post-dispersal performance with dispersal distance (Futuyma and Moreno 1988, Stamps et al. 2005). This mechanism is independent of the determinants of site quality and may explain how variation in dispersal distance is maintained in diverse species. However, if 


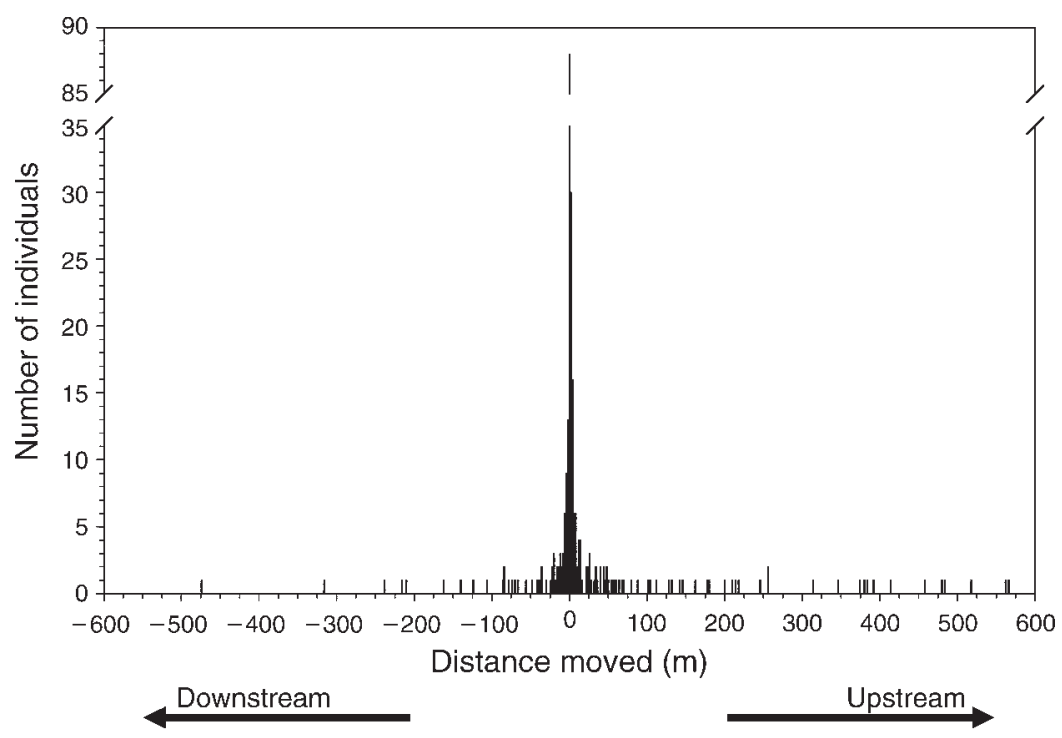

FIG. 1. Movement distribution of the stream salamander Gyrinophilus porphyriticus in Merrill Brook, a first-order stream in northern New Hampshire, USA. Data are from individuals recaptured between 1999 and $2004(n=221)$ in surveys conducted each June, July, and August and are pooled over all recapture intervals.

individuals do not benefit from increasing dispersal distance, it would suggest that the similarity of movement distributions across species is spurious, resulting from stochastic or system-specific mechanisms (Carlquist 1981, Muller-Landau et al. 2003). Until now, low detectability of LDD and small post-dispersal sample sizes have precluded testing these relationships (Koenig et al. 1996, Nathan 2005).

In this study I used six years of spatially explicit capture-mark-recapture (CMR) data to test the prediction that individual performance increases with dispersal distance in the stream salamander Gyrinophilus porphyriticus (see Plate 1). The study system has two properties that are critical to overcoming detection-related obstacles to research on LDD. First, vagility of G. porphyriticus is low, so surveys can detect dispersal events that are long-distance and rare relative to the majority of movements (Fig. 1; Lowe 2003, 2009). Second, G. porphyriticus is constrained to linear stream corridors; larvae are restricted to the stream channel, and although adults can move short distances into riparian forests at night ( $<3 \mathrm{~m}$ from the stream, on average), they return to the stream during the day (Greene et al. 2008). The probability of detecting marked animals declines with movement distance in two-dimensional landscapes (Koenig et al. 1996), but when movement is along linear habitats such as stream corridors and sampling is consistent throughout the available habitat (e.g., from bank to bank), detection probability is not affected by movement distance (Pollock et al. 2002).

To quantify individual performance, I used CMR estimates of relative survival and individual growth rates based on change in body length (snout-vent length, SVL). Reproductive output increases significantly with
SVL in G. porphyriticus (Bruce 1978). However, G. porphyriticus is long-lived (maximum age from skeletochronology is 14 years; W. H. Lowe, unpublished data) and both annual recruitment and the proportion of larvae in populations are low (Lowe 2003), suggesting that survival is the major determinant of lifetime fitness (Roff 2002). My results show that individual survival and growth increase with dispersal distance in $G$. porphyriticus and thus do not support the view that LDD is stochastic, with unpredictable fitness consequences. Instead, they suggest that consistent evolutionary mechanisms may explain the prevalence of LDD in natural populations.

\section{Methods}

\section{Study species and site}

Gyrinophilus porphyriticus belongs to the family Plethodontidae, the lungless salamanders. This species is found in small, cool, well-oxygenated streams along the Appalachian uplift, from central Alabama to southern Quebec (Petranka 1998). The larval period is estimated to be 3-5 years (Bruce 1980). During the day, larvae and adults are found in interstitial spaces among the larger substrate particles of the streambed. In the northern Appalachians, larval size range is $26-80 \mathrm{~mm}$ SVL, adults can reach $120 \mathrm{~mm} \mathrm{SVL}$, and both stages feed primarily on invertebrates (Greene et al. 2008).

The study site was Merrill Brook, a fishless, firstorder stream in Dartmouth College's Second College Grant, located in northern New Hampshire, USA. Merrill Brook flows into the fourth-order Dead Diamond River; a wetland at the confluence serves as a barrier to brook trout (Salvelinus fontinalis) that might enter Merrill Brook from the larger river. 
Sampling occurred throughout a $1 \mathrm{~km}$ long section of Merrill Brook that started at the confluence with the outflow wetland and ended $1000 \mathrm{~m}$ upstream of that point, encompassing the perennial portion of the stream. Undisturbed headwater streams in New Hampshire display low conductivity $(12.0-15.0 \mu \mathrm{S} / \mathrm{cm})$, slight acidity ( $\mathrm{pH}$ of 5.0-6.0), high dissolved oxygen content (80-90\% saturation), and moderate midday temperatures in the summer $\left(13.0-17.0^{\circ} \mathrm{C}\right)$ (Likens and Bormann 1995). Sampling throughout Merrill Brook matched these data. Other salamanders encountered in Merrill Brook were Eurycea bislineata and Desmognathus fuscus (both Plethodontidae).

\section{Survey methods}

I conducted surveys of Merrill Brook during threeday periods in mid-June, mid-July, and mid-August of 1999-2004, resulting in a total of 18 surveys. A covercontrolled, active search sampling method was used (Heyer et al. 1994). Moving upstream, I turned rocks within the channel and along the edge measuring between 64 and $256 \mathrm{~mm}$ in diameter (cobble); surveys continued until 1200 rocks had been turned. The even distribution of cobble allowed for a constant effort of just over one rock per meter of stream length, so surveys provided spatially explicit information on individual salamanders encountered throughout the stream. An aquarium dip-net was used to capture salamanders, including those flushed by the current.

All unmarked $G$. porphyriticus larvae and adults encountered were individually marked by subcutaneous injection of fluorescent elastomer (Northwest Marine Technologies, Shaw Island, Washington, USA). Retention of these marks is high throughout the life of the animals (Grant 2008). The longitudinal position (distance from the confluence, in meters), length (SVL, in millimeters), and mass (in milligrams) of all individuals encountered were recorded. Salamanders were distributed randomly along Merrill Brook (Morisita dispersion index $\sim 1.0$ ), not aggregated into a subset of $10-\mathrm{m}$ reaches (Lowe 2009).

\section{Quantifying dispersal distance}

I used data from recaptured animals to quantify individual variation in dispersal distance. Dispersal distance was the total distance moved (in meters along the stream, with 1-m accuracy) over the six-year study period. In Merrill Brook and 15 streams where shorter mark-recapture studies were conducted (1-2 years), there were no differences in movement distributions related to size (SVL), life history stage (larva vs. adult), or sex. Further, there was no within-year variation in movement distributions associated with stream flow (Lowe 2003, Lowe et al. 2006). These findings allowed me to pool movement data across sizes, life history stages, sexes, and time. Relative to the major ecological and morphological differences between life history stages in other amphibians, larvae and adults of $G$. porphyriticus are very similar (Petranka 1998), which may explain the similarity of movement patterns and demographic parameters in the two stages (Lowe 2003).

Of the animals recaptured more than once over the six years $(n=109)$, only one moved from a capture location and subsequently returned to that location (Lowe 2009). None of the other animals moved and then returned to a previous location, whether movement was $1 \mathrm{~m}$ or more than $100 \mathrm{~m}$, indicating that the majority of movements were unidirectional dispersal events, as opposed to temporary movements. This justified combining movement data from individuals recaptured once with data from individuals recaptured multiple times. To determine whether variation in the number of times an individual was recaptured affected dispersal distance estimates, I tested for a correlation between number of recaptures and dispersal distance using Spearman rank correlation analysis $\left(r_{\mathrm{S}}\right)$.

\section{Testing the effect of dispersal distance on survival}

I used Cormack-Jolly-Seber (CJS) CMR models in Program MARK (White and Burnham 1999) to model monthly apparent survival $(\phi)$ and capture probability $(p)$ of recaptured animals. Apparent survival probability represents the probability that an animal alive at time $t$ will be alive at time $t+1$. Capture probability is the probability that a marked animal at risk of capture at time $t$ is captured at $t$. Estimates of $\phi$ from CJS models confound mortality with permanent emigration from the population. However, no $G$. porphyriticus individuals were found in yearly sampling of the outflow wetland and upper ephemeral portion of Merrill Brook (Lowe 2003), indicating that the study section encompassed all available habitat and that the population was largely closed with regard to emigration. Because the nearest occupied stream was $3 \mathrm{~km}$ away, I assumed that immigration did not occur at a demographically significant rate.

Individuals that were never recaptured were removed from the data set so that both non-dispersers (dispersal distance $=0 \mathrm{~m}$ ) and dispersers (dispersal distance $\geq 1 \mathrm{~m}$ ) were recaptured at least once. This allowed me to compare relative apparent survival of both nondispersers and dispersers, but consistently biased absolute estimates of apparent survival. Because all individuals were recaptured at least once, this analysis does not provide information on survival during the first recapture interval.

I first modeled survival and capture probabilities as constant or variable over time (survey date). Previous CMR analyses showed no difference in survival probabilities of larvae and adults (Lowe 2003), so I did not include life history stage in these models. I used Akaike's information criterion (AIC; Akaike 1973) to identify the model that represented the data adequately with as few parameters as possible. Models were ranked by second-order $\mathrm{AIC}\left(\mathrm{AIC}_{\mathrm{c}}\right)$ differences $\left(\triangle \mathrm{AIC}_{\mathrm{c}}\right.$; Burnham and Anderson 2002). Relative likelihood of each 


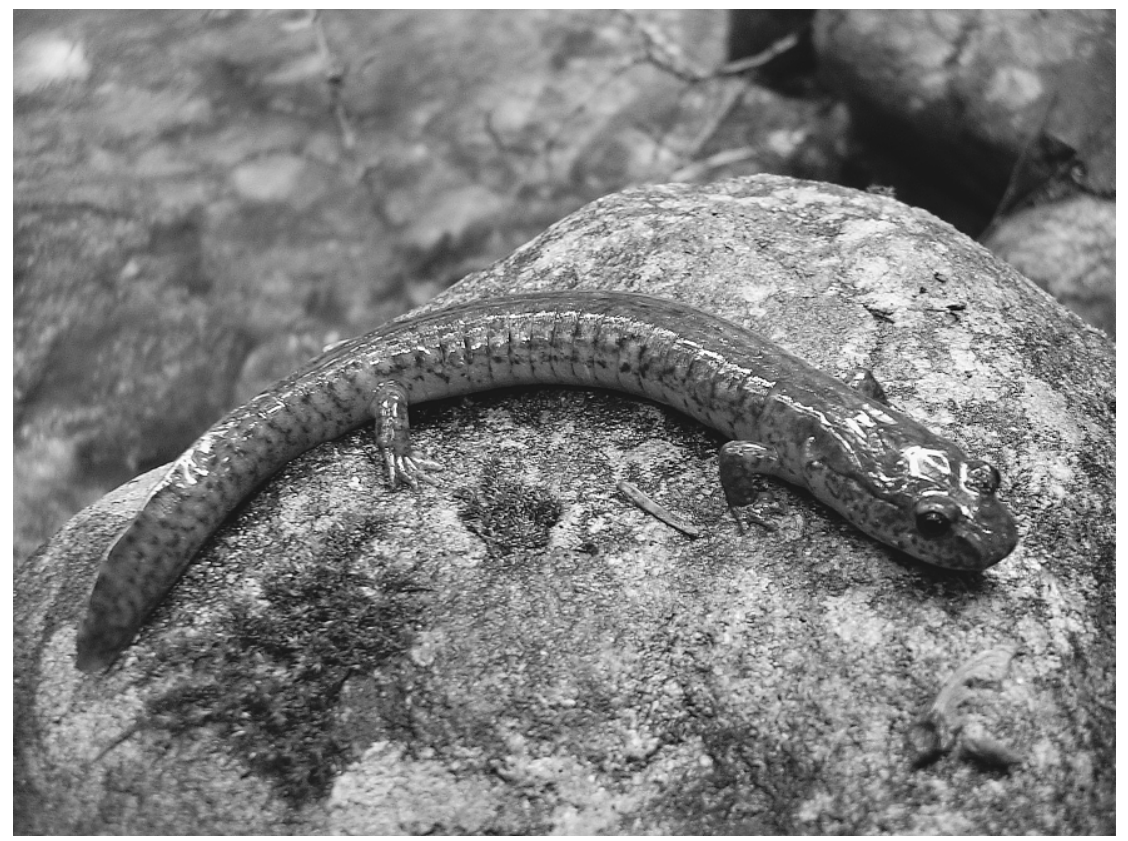

Plate 1. The spring salamander, Gyrinophilus porphyriticus (Green), a headwater specialist found along the Appalachian uplift of eastern North America. Photo credit: Bradley J. Cosentino.

model in the candidate set was then estimated with $\mathrm{AIC}_{\mathrm{c}}$ weights (Buckland et al. 1997).

Dispersal distance ([in meters] +1 , log-transformed) was added as an individual covariate to the best model from this initial analysis. By using dispersal distance as an individual covariate, I was able to test whether model likelihood increased when monthly survival and capture probabilities were functions of dispersal distance (Pollock 2002). When models with individual covariates are supported, Program MARK reconstitutes parameter estimates and associated confidence intervals across the observed range of the covariate, allowing visualization of the functional relationship. I used a logit link to ensure that $\phi$ and $p$ ranged from 0 to 1 .

\section{Testing the effect of dispersal distance on individual growth}

I calculated proportional daily growth rates of body length (SVL, in millimeters) over the cumulative recapture interval. I used Pearson product-moment correlation analysis to test the assumption that growth rate was unrelated to the initial SVL of recaptured animals (Schoener and Schoener 1978, Kaufmann 1981). I used linear regression analysis to test the prediction that dispersal distance was positively related to growth rate. Proportional daily growth rates were arcsine square-root transformed.

Before testing for an effect of dispersal distance on individual growth rate, I assessed potential correlates of dispersal distance and growth rate that might confound this test or the CMR analyses. I first tested for correlation between dispersal distance and the initial body condition of recaptured animals. Log-transformed SVL and mass measurements were used to calculate initial size-corrected mass (following recommendations in Green [2001]), an index of body condition in $G$. porphyriticus that, in previous studies, was found to be positively correlated with survival (Lowe 2003) and individual growth rate (Lowe et al. 2006). If initial body condition was correlated with dispersal distance, it would be impossible to isolate effects of dispersal distance on survival and growth from factors that affected individuals prior to dispersal (Stamps and Davis 2006, Benard and McCauley 2008).

I also tested for correlation between growth rate and the final location (in meters along the stream) of recaptured animals. A correlation between growth rate and final location would signal a gradient in local conditions along the stream (e.g., conspecific density, water temperature, $\mathrm{pH}$ ) and confound any relationship between dispersal distance and individual performance with that gradient. A lack of correlation between these variables would indicate that individual performance was not mediated by large-scale gradients along the stream, but instead by patchy, fine-scale variation in local conditions typical of a wide array of both terrestrial and aquatic systems.

\section{RESUlts}

Over the six-year study period, I marked $972 \mathrm{G}$. porphyriticus and recaptured 221 individuals. Of the recaptured individuals, 84 were first captured as larvae and 137 were first captured as adults. Of those individuals that were first captured as larvae, 32 were 
TABLE 1. Cormack-Jolly-Seber (CJS) models of monthly apparent survival $(\phi)$ and capture $(p)$ probabilities of the stream salamander Gyrinophilus porphyriticus in Merrill Brook, New Hampshire, USA: (A) without dispersal distance as an individual covariate and (B) with dispersal distance as an individual covariate, and the best model without dispersal distance.

\begin{tabular}{|c|c|c|c|c|}
\hline Model & $\mathrm{AIC}_{\mathrm{c}}$ & $\Delta \mathrm{AIC}_{\mathrm{c}}$ & AIC weight & $\bar{K}$ \\
\hline \multicolumn{5}{|l|}{ A) Without dispersal distance covariate } \\
\hline$\phi(\cdot), p($ time $)$ & 1757.82 & 0.00 & 0.91 & 18 \\
\hline$\phi(\cdot), p(\cdot)$ & 1762.33 & 4.51 & 0.09 & 2 \\
\hline$\phi($ time $), p($ time $)$ & 1779.54 & 21.72 & 0.00 & 34 \\
\hline$\phi($ time $), p(\cdot)$ & 1781.86 & 24.05 & 0.00 & 18 \\
\hline \multicolumn{5}{|l|}{ B) With dispersal distance covariate } \\
\hline$\phi(\cdot$, distance $), p\left(\right.$ time, distance $\left._{\text {time-invariant intercept }}\right)$ & 1726.76 & 0.00 & 0.99 & 20 \\
\hline$\phi(\cdot$, distance $), p($ time, distance time-variant intercept $)$ & 1735.53 & 8.77 & 0.01 & 36 \\
\hline$\phi(\cdot), p($ time $)$ & 1757.82 & 31.05 & 0.00 & 18 \\
\hline
\end{tabular}

Notes: Second-order corrected Akaike information criterion values $\left(\mathrm{AIC}_{\mathrm{c}}\right), \mathrm{AIC}_{\mathrm{c}}$ differences $\left(\Delta \mathrm{AIC}_{\mathrm{c}}\right), \mathrm{AIC}_{\mathrm{c}}$ weights, and numbers of estimable parameters $(K)$ are provided for all models. Parameterization for $\phi$ and $p$ is in parentheses: "." indicates constant by time (survey date); "time" indicates variation by time; "distance" indicates variation by dispersal distance ([in meters] $+1, \log$ transformed). Subscripts indicate whether the functional relationship between dispersal distance and $p$ was modeled with a time-invariant or a time-variant intercept.

recaptured as adults. Dispersal distances ranged from 0 to $565 \mathrm{~m}$ (Fig. 1) and $25 \%$ of recaptured individuals moved $\leq 1 \mathrm{~m}$ from their initial locations. There was no correlation between number of captures and dispersal distance $\left(r_{\mathrm{S}}=0.11, n=221, P>0.10\right)$, indicating that the majority of movements were discrete dispersal-andsettlement events.

\section{The effect of dispersal distance on survival}

The initial CMR analysis estimating monthly apparent survival $(\phi)$ and capture probability $(p)$ indicated that the saturated model (time-variant $\phi$ and $p$ ) fit the data very well. Based on 1000 bootstrap iterations, the probability of observing model deviance as large as the saturated model was 0.99 . Therefore, no adjustment to the $\mathrm{AIC}_{\mathrm{c}}$ scores for over-dispersion $(\hat{c})$ was necessary (Burnham and Anderson 2002). The best model had time-invariant $\phi$ and time-variant $p$ and fit the data more than 10 times as well as the second-best-fitting model (Table 1A).

Dispersal distance was subsequently added as an individual covariate in this best-fitting model. Because $\phi$ was time invariant in the best-fitting initial model, the functional relationship between dispersal distance and $\phi$ was modeled with time-invariant slope and intercept. Because $p$ was time variant in the best-fitting initial model, the functional relationship between dispersal distance and $p$ was modeled with time-variant slope and both time-variant and time-invariant intercept.

The most parsimonious model that included dispersal distance as an individual covariate fit the data more than 99 times as well as the best model without dispersal distance as a covariate (Table 1B). It also fit the data 99 times as well as the second-best-fitting model that included dispersal distance as an individual covariate. In the most supported model, relative apparent survival increased with dispersal distance (Fig. 2A). This analysis controlled for the relationship between capture probability and dispersal distance, and the lack of correlation between number of captures and dispersal distance indicates that this relationship was weak.

\section{The effect of dispersal distance on individual growth}

Proportional daily growth rate increased with dispersal distance $\left(F_{1,219}=10.98, r^{2}=0.05, P=0.001\right.$; Fig. 2B). Growth rate was unrelated to the initial SVL of
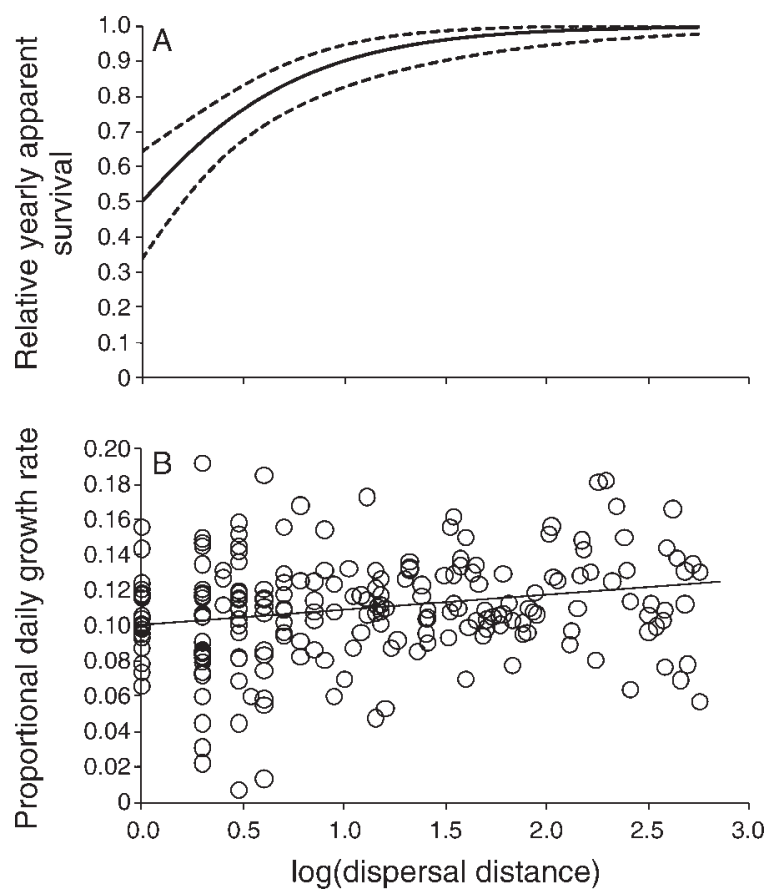

FIG. 2. The effects of dispersal distance ([in meters $]+1, \log -$ transformed) on (A) relative yearly apparent survival (estimate and $95 \%$ confidence interval) and (B) proportional daily growth rate for snout-vent length $(\mathrm{mm}$; arcsine square-root transformed) of Gyrinophilus porphyriticus individuals in Merrill Brook. Apparent yearly survival estimates were calculated using estimates of apparent monthly survival $(\phi)$ from Cormack-Jolly-Seber models implemented in Program MARK (Table 1). 
recaptured animals $(r<0.01, n=221, P>0.50)$, and this result did not change when I analyzed animals that were initially marked as larvae separately from those that were initially marked as adults. Also, dispersal distance was not correlated with the initial body condition of recaptured animals $(r=-0.03, n=221, P$ $=0.70$ ), and growth rate was unrelated to the final location of recaptured animals $(r=-0.05, n=221, P=$ $0.43)$.

\section{Discussion}

This study provides novel insight into the individual consequences of continuous variation in dispersal distance. Survival and growth rate of G. porphyriticus individuals increased with dispersal distance (Fig. 2), supporting the prediction that individual performance increases with dispersal distance. Dispersal distance had a strong effect on relative apparent survival (Fig. 2A), which life history and field data suggest is the major determinant of lifetime fitness. Much of the variance in individual growth rates was unexplained by dispersal distance, but the positive relationship with dispersal distance was highly significant (Fig. 2B), corresponding to a threefold increase in proportional daily growth rate across the range of dispersal distances.

Dispersal distance was unrelated to initial body condition of recaptured animals, indicating that movement behavior was independent of factors affecting individuals prior to initial capture (Stamps and Davis 2006, Benard and McCauley 2008). Because body condition is known to be correlated with survival and growth in G. porphyriticus (Lowe 2003, Lowe et al. 2006), this also supports the interpretation that survival and growth were affected by dispersal distance (Fig. 2) and not determined by pre-dispersal performance. Individual growth rates were unrelated to the final locations of recaptured animals along the stream. This indicates that effects of dispersal distance on survival and growth were not confounded by ecological gradients along the study stream and suggests that spatial variation in site quality along Merrill Brook is random. If dispersers were more likely to emigrate, then apparent survival would decrease with dispersal distance. However, apparent survival showed the opposite pattern (Fig. 2A), supporting the assumption that emigration did not affect these estimates.

These results show that individuals that were able to disperse relatively long distances settled in sites where survival and growth were highest (Fig. 2). In contrast, individuals that did not disperse or dispersed short distances were more likely to be in suboptimal sites where performance was compromised. Because I did not find evidence of an overarching performance gradient in the study stream, it is likely the benefits of LDD were related to an increase in the number of potential settlement sites with dispersal distance. Assuming that the determinants of site quality exhibit only fine-scale spatial autocorrelation within the stream and are otherwise randomly distributed, then as the number of potential settlement sites increases, so should the range of overall site quality (Koenig 1999). A capacity for LDD should therefore increase the upper limit of settlement site quality and resulting post-dispersal performance, especially in species that can detect and avoid low-quality sites. However, if site quality is randomly distributed, there is a low probability that an individual will find a high-quality site without moving far, which may account for some of the residual variance in Fig. 2B.

In light of the benefits of increasing dispersal distance (Fig. 2), the observation that all individuals do not disperse long distances (Fig. 1) suggests that individuals differ in their ability to withstand costs incurred during dispersal or assess site quality (Johnson and Gaines 1990, Stamps et al. 2005). Specifically, individual differences in the ability to withstand dispersal costs or accurately determine site quality (either of sites that are currently occupied or those encountered during dispersal) may cause long-distance dispersal to remain rare even when there are predictable benefits of increasing dispersal distance. In headwater streams throughout the Appalachians, brook trout prey on small size classes of G. porphyriticus and reduce growth rates of larger size classes through interference competition (Resetarits 1991, 1995, Lowe et al. 2004). Gyrinophilus porphyriticus individuals reduce their activity in the presence of brook trout to avoid these negative interactions, strongly suggesting that the active movement required for dispersal has energetic and survival costs in streams with trout (e.g., Gaines and McClenaghan 1980, Lima and Zollner 1996). Because exposure time increases with dispersal distance, these costs are likely to be distance dependent. Although Merrill Brook is fishless, variation among individuals in the ability to avoid other predators during dispersal, resulting from crypsis, sensory acuity, or other traits, may reduce the frequency of LDD. Variation in traits mediating site selectivity would have a similar effect, underscoring the complex fitness tradeoffs that underlie cumulative distributions of dispersal distance (e.g., Fig. 1).

Conspecific density can play an important role in driving dispersal and determining its outcome (Travis et al. 1999, Matthysen 2005). However, G. porphyriticus occurs at low densities throughout Merrill Brook $(<1$ individual $/ 2 \mathrm{~m}^{2}$ ), and previous analyses showed no relationship between density and movement behavior (Lowe 2009). This suggests that conspecific density is not an important determinant of settlement site quality and associated survival and growth responses (Fig. 2). If abiotic conditions that exhibit longitudinal gradients in streams were important determinants of site quality (e.g., temperature, $\mathrm{pH}$, and conductivity), then growth rate should have been correlated with the final location of recaptured individuals, which was not the case. Settlement site quality may be a function of invertebrate prey availability or flow microhabitats, both of which 
vary at fine spatial scales in streams (e.g., 1-5 m; Allan and Castillo 2007). Determinants of site quality may be different in streams with fish, where subsurface refuges and foraging sites are likely to be important (Sih et al. 1992). Most G. porphyriticus individuals move very little (Fig. 1), and shorter movements $(\leq 10 \mathrm{~m})$ show no temporal pulses that might indicate inbreeding avoidance (Lowe 2003, Lowe et al. 2006). Therefore, any fitness costs of inbreeding would likely add to the benefits of LDD in this system.

Intrapopulation variation in behavioral phenotypes can lead to leptokurtic movement distributions, where the large tails result from a subpopulation of bold "movers" and the high peaks are comprised of less-bold "stayers" (Fraser et al. 2001). Variation in dispersal distance may also be caused by other phenotypic polymorphisms (e.g., Harrison 1980) or by habitat structure and quality (e.g., Morales 2002). In G. porphyriticus, spatial and temporal variation in habitat quality influences the frequency of LDD (Lowe 2009), and a movement-related polymorphism may explain the consistent leptokurtosis of movement distributions (Lowe 2003, Lowe et al. 2006). However, independent of the causes of variation in dispersal distance, this study shows that continuous variation in dispersal distance is associated with continuous variation in individual performance (Fig. 2). It therefore also shows the importance of understanding how discrete dispersal polymorphisms evolve and how the causes and consequences of variation in dispersal distance are evolutionarily linked.

The positive effects of dispersal distance on $G$. porphyriticus survival and growth suggest that the prevalence of leptokurtic movement distributions in diverse species may be explained by consistent mechanisms (Endler 1977, Johnson and Gaines 1990). Specifically, my results show that there are predictable benefits of LDD in this study system, suggesting that there may be selection for phenotypic traits that allow for LDD. These results offer an alternative to the view that LDD is primarily mediated by stochastic mechanisms and thus highly unpredictable in occurrence and outcome (Carlquist 1981). Although the evolution of dispersal as a categorical response (i.e., stay vs. move) has been addressed in theoretical and empirical studies (e.g., McPeek and Holt 1992, Friedenberg 2003), to my knowledge this is the first empirical study to show the effects of continuous variation in dispersal distance on individual survival and growth.

Efforts to understand the causes and consequences of dispersal have produced a large body of theory. However, the difficulty of observing dispersal directly and the wide range of dispersal mechanisms and population distributions that exist make it difficult to test this theory, resulting in a gap between theory and empirical data on dispersal. Theory should outpace and inspire empirical research, but as emphasized in reviews (e.g., Johnson and Gaines 1990, Clobert et al. 2001,
Nathan 2006), the persistence of this gap risks creating two largely independent bodies of work on this important topic. I hope my results bridge this gap, showing that direct data on animal movement can help us understand the individual consequences of variation in dispersal distance and how that variation is maintained in natural populations.

\section{ACKNOWLEDGMENTS}

This research was funded by the Sweet Water Trust, the National Science Foundation (DEB-0105091), and the Andrew W. Mellon Foundation. I am grateful for support from L. Turner, K. Evans, L. Greene, C. Shannon, C. Glastris, A. Margolis, B. Fisher, J. Tollefson, W. Lowe, and I. Lowe. This manuscript was improved with comments from F. Allendorf, S. Mills, B. Hossack, A. Sepulveda, A. Flesch, M. Machura, and L. Mullen.

\section{Literature Cited}

Akaike, H. 1973. Information theory as an extension of the maximum likelihood principle. Pages 267-281 in Second international symposium on information theory. Akademiai Kiado, Budapest, Hungary.

Allan, J. D., and M. M. Castillo. 2007. Stream ecology: structure and function of running waters. Springer, Dordrecht, The Netherlands.

Benard, M. F., and S. J. McCauley. 2008. Integrating across life-history stages: consequences of natal habitat effects on dispersal. American Naturalist 171:553-567.

Bruce, R. C. 1978. Life-history patterns of salamander Gyrinophilus porphyriticus in Cowee Mountains, North Carolina. Herpetologica 34:53-64.

Bruce, R. C. 1980. A model of the larval period of the spring salamander, Gyrinophilus porphyriticus, based on size-frequency distributions. Herpetologica 36:78-86.

Buckland, S. T., K. P. Burnham, and N. H. Augustin. 1997. Model selection: an integral part of inference. Biometrics 53: 603-618.

Burnham, K. P., and D. R. Anderson. 2002. Model selection and inference: a practical information-theoretic approach. Springer, New York, New York, USA.

Carlquist, S. 1981. Chance dispersal. American Scientist 69: 509-516.

Caswell, H., R. Lensink, and M. G. Neubert. 2003. Demography and dispersal: life table response experiments for invasion speed. Ecology 84:1968-1978.

Clobert, J., E. Danchin, A. A. Dhondt, and J. D. Nichols, editors. 2001. Dispersal. Oxford University Press, Oxford, UK.

Darwin, C. 1859. The origin of species by means of natural selection. John Murray, London, UK.

Dytham, C. 2009. Evolved dispersal strategies at range margins. Proceedings of the Royal Society B 276:1407-1413.

Endler, J. A. 1977. Geographic variation, speciation and clines. Princeton University Press, Princeton, New Jersey, USA.

Fraser, D. F., J. F. Gilliam, M. J. Daley, A. N. Le, and G. T. Skalski. 2001. Explaining leptokurtic movement distributions: intrapopulation variation in boldness and exploration. American Naturalist 158:124-135.

Friedenberg, N. A. 2003. Experimental evolution of dispersal in spatiotemporally variable microcosms. Ecology Letters 6: 953-959.

Futuyma, D. J., and G. Moreno. 1988. The evolution of ecological specialization. Annual Review of Ecology and Systematics 19:207-233.

Gaines, M. S., and L. R. McClenaghan. 1980. Dispersal in small mammals. Annual Review of Ecology and Systematics 11:163-196. 
Grant, E. H. C. 2008. Visual implant elastomer mark retention through metamorphosis in amphibian larvae. Journal of Wildlife Management 72:1247-1252.

Green, A. J. 2001. Mass/length residuals: Measures of body condition or generators of spurious results? Ecology 82:14731483.

Greene, B. T., W. H. Lowe, and G. E. Likens. 2008. Forest succession and prey availability influence the strength and scale of terrestrial-aquatic linkages in a headwater salamander system. Freshwater Biology 53:2234-2243.

Hansson, B., S. Bensch, and D. Hasselquist. 2004. Lifetime fitness of short- and long-distance dispersing great reed warblers. Evolution 58:2546-2557.

Harrison, R. G. 1980. Dispersal polymorphisms in insects. Annual Review of Ecology and Systematics 11:95-118.

Heyer, W. R., M. A. Donnelly, R. W. McDiarmid, L. C. Hayek, and M. S. Foster. 1994. Measuring and monitoring biodiversity: standard methods for amphibians. Smithsonian Institution Press, Washington, D.C., USA.

Holyoak, M., R. Casagrandi, R. Nathan, E. Revilla, and O. Spiegel. 2008. Trends and missing parts in the study of movement ecology. Proceedings of the National Academy of Sciences USA 105:19060-19065.

Holyoak, M., M. A. Leibold, and R. D. Holt, editors. 2005. Metacommunities: spatial dynamics and ecological communities. University of Chicago Press, Chicago, Illinois, USA.

Johnson, M. L., and M. S. Gaines. 1990. Evolution of dispersal: theoretical models and empirical tests using birds and mammals. Annual Review of Ecology and Systematics 21: 449-480.

Kaufmann, K. W. 1981. Fitting and using growth curves. Oecologia 49:293-299.

Koenig, W. D. 1999. Spatial autocorrelation of ecological phenomena. Trends in Ecology and Evolution 14:22-26.

Koenig, W. D., D. VanVuren, and P. N. Hooge. 1996. Detectability, philopatry, and the distribution of dispersal distances in vertebrates. Trends in Ecology and Evolution 11: 514-517.

Likens, G. E., and F. H. Bormann. 1995. Biogeochemistry of a forested ecosystem. Springer, New York, New York, USA.

Lima, S. L., and P. A. Zollner. 1996. Towards a behavioral ecology of ecological landscapes. Trends in Ecology and Evolution 11:131-135.

Lowe, W. H. 2003. Linking dispersal to local population dynamics: a case study using a headwater salamander system. Ecology 84:2145-2154.

Lowe, W. H. 2009. What drives long-distance dispersal? A test of theoretical predictions. Ecology 90:1456-1462.

Lowe, W. H., G. E. Likens, and B. J. Cosentino. 2006. Selforganisation in streams: the relationship between movement behaviour and body condition in a headwater salamander. Freshwater Biology 51:2052-2062.

Lowe, W. H., K. H. Nislow, and D. T. Bolger. 2004. Stagespecific and interactive effects of sedimentation and trout on a headwater stream salamander. Ecological Applications 14: 164-172.

Matthysen, E. 2005. Density-dependent dispersal in birds and mammals. Ecography 28:403-416.
McPeek, M. A., and R. D. Holt. 1992. The evolution of dispersal in spatially and temporally varying environments. American Naturalist 140:1010-1027.

Morales, J. M. 2002. Behavior at habitat boundaries can produce leptokurtic movement distributions. American Naturalist 160:531-538.

Muller-Landau, H. C., S. A. Levin, and J. E. Keymer. 2003. Theoretical perspectives on evolution of long-distance dispersal and the example of specialized pests. Ecology 84: 1957-1967.

Nathan, R. 2005. Long-distance dispersal research: building a network of yellow brick roads. Diversity and Distributions 11:125-130.

Nathan, R. 2006. Long-distance dispersal of plants. Science 313:786-788.

Petranka, J. W. 1998. Salamanders of the United States and Canada. Smithsonian Institution Press, Washington, D.C., USA.

Pollock, K. H. 2002. The use of auxiliary variables in capturerecapture modelling: an overview. Journal of Applied Statistics 29:85-102.

Pollock, K. H., J. D. Nichols, T. R. Simons, G. L. Farnsworth, L. L. Bailey, and J. R. Sauer. 2002. Large scale wildlife monitoring studies: statistical methods for design and analysis. Environmetrics 13:105-119.

Pulliam, H. R., and B. J. Danielson. 1991. Sources, sinks, and habitat selection: a landscape perspective on population dynamics. American Naturalist 137:S50-S66.

Resetarits, W. J. 1991. Ecological interactions among predators in experimental stream communities. Ecology 72:1782-1793.

Resetarits, W. J. 1995. Competitive asymmetry and coexistence in size-structured populations of brook trout and spring salamanders. Oikos 73:188-198.

Roff, D. A. 2002. Life history evolution. Sinauer, Sunderland, Massachusetts, USA.

Schoener, T. W., and A. Schoener. 1978. Estimating and interpreting body-size growth in some Anolis lizards. Copeia 1978:390-405.

Sih, A., L. B. Kats, and R. D. Moore. 1992. Effects of predatory sunfish on the density, drift, and refuge use of stream salamander larvae. Ecology 73:1418-1430.

Stamps, J. A., and J. M. Davis. 2006. Adaptive effects of natal experience on habitat selection by dispersers. Animal Behaviour 72:1279-1289.

Stamps, J. A., V. V. Krishnan, and M. L. Reid. 2005. Search costs and habitat selection by dispersers. Ecology 86:510518.

Trakhtenbrot, A., R. Nathan, G. Perry, and D. M. Richardson. 2005. The importance of long-distance dispersal in biodiversity conservation. Diversity and Distributions 11:173-181.

Travis, J. M. J., D. J. Murrell, and C. Dytham. 1999. The evolution of density-dependent dispersal. Proceedings of the Royal Society B 266:1837-1842.

White, G. C., and K. P. Burnham. 1999. Program MARK: survival estimation from populations of marked animals. Bird Study 46:120-139.

Wright, S. 1951. The genetical structure of natural populations. Annals of Eugenics 15:323-354. 